\title{
Influence of Hydrodynamic Flow Patterns on the Corrosion Behavior of Carbon Steel in a Neutral LiBr Solution
}

\author{
Alvaro Soliz, ${ }^{1, *}$ Karl J.J. Mayrhofer ${ }^{2}$, Luis Cáceres ${ }^{3}$ \\ ${ }^{1}$ Departamento de Ingeniería en Metalurgia, Facultad de Ingeniería, Universidad de Atacama, Av. \\ Copayapu 485, 1532297 Copiapó, Chile \\ ${ }^{2}$ Department of Interface Chemistry and Surface Engineering, Max-Planck-Institut für Eisenforschung \\ GmbH, Max-Planck-Straße 1, 40237 Düsseldorf, Germany \\ ${ }^{3}$ Departamento de Ingeniería Química y Procesos de Minerales, Center for Biotechnology and \\ Bioengineering, Universidad de Antofagasta, Av. Universidad de Antofagasta s/n, Antofagasta, Chile \\ *E-mail: alvaro.soliz@uda.cl
}

doi: $10.20964 / 2018.11 .08$

Received: 5 July 2018 / Accepted: 11 August 2018 / Published: 1 October 2018

\begin{abstract}
The present study investigated the corrosion behavior of carbon steel samples using two electrochemical cell types that operate with distinctly different fluid flow patterns. For this purpose, an annular flow cell and a rotating disc electrode were used to investigate the influence of the immersion time on the corrosion kinetics of carbon steel in an aerated $0.5 \mathrm{M} \mathrm{LiBr}$ solution. The electrochemical results show good data reproducibility for both experimental cells. In both of these cells, the corrosion rate increases to a maximum value, and it gradually decreases with the immersion time. This shift in the corrosion rate is associated with a series of competing reaction mechanisms, which include a significant oxygen concentration reduction at the metal-solution interface, changes in the corrosion regime and oxide phase transformations. These competing reactions were described in terms of electrochemical kinetic parameters for partial reactions and equivalent circuits determined from polarization curves and electrochemical impedance spectroscopy measurements. The kinetic analysis shows that the oxygen reduction reaction is highly affected by the immersion time in solution, where non-realistic kinetic parameter values are found for long immersion times. Furthermore, the corrosion morphology found on the tested samples confirms the aggressive behavior of bromide ions, which promotes a pitting corrosion with a lateral spread of corrosion products.
\end{abstract}

Keywords: Carbon steel; Kinetic parameters; Pitting corrosion; Polarization 
(C) 2018 The Authors. Published by ESG (www.electrochemsci.org). This article is an open access article distributed under the terms and conditions of the Creative Commons Attribution license (http://creativecommons.org/licenses/by/4.0/). 